\title{
Outcomes of critically ill patients according to the perception of intensivists on the appropriateness of intensive care unit admission
}

\author{
Youjin Chang' ${ }^{1}$, Kyoung Ran $\mathrm{Kim}^{2}$, Jin Won Huh ${ }^{3}$, Sang-Bum Hong ${ }^{3}$, Younsuck Koh ${ }^{3}$, Chae-Man Lim ${ }^{3}$ \\ ${ }^{1}$ Division of Pulmonary and Critical Care Medicine, Department of Internal Medicine, Sanggye Paik Hospital, Inje University College of Medicine, Seoul; ${ }^{2}$ Medical \\ Intensive Care Unit, Asan Medical Center, Seoul; ${ }^{3}$ Department of Pulmonary and Critical Care Medicine, Asan Medical Center, University of Ulsan College of \\ Medicine, Seoul, Korea
}

Background: It is important for intensivists to determine which patient may benefit from intensive care unit (ICU) admission. We aimed to assess the outcomes of patients perceived as non-beneficially or beneficially admitted to the ICU and evaluate whether their prognosis was consistent with the intensivists' perception.

Methods: A prospective observational study was conducted on patients admitted to the medical ICU of a tertiary referral center between February and April 2014. The perceptions of four intensivists at admission (day 1) and on day 3 were investigated as non-beneficial admission, beneficial admission, or indeterminate state.

Results: A total of 210 patients were enrolled. On days 1 and 3, 22 (10\%) and 23 (11\%) patients were judged as having non-beneficial admission; 166 (79\%) and 159 (79\%), beneficial admission; and $22(10 \%)$ and $21(10 \%)$, indeterminate state, respectively. The ICU mortality rates of each group on day 1 were 59\%, 23\%, and 59\%, respectively; their 6-month mortality rates were 100\%, $48 \%$, and $82 \%$, respectively. The perceptions of non-beneficial admission or indeterminate state were the significant predictors of ICU mortality (day 3 : odds ratio [OR], 4.049; 95\% confidence interval [Cl], 1.892-8.664; $\mathrm{P}<0.001$ ) and 6-month mortality (day $1: 0 \mathrm{R}, 4.983 ; 95 \% \mathrm{Cl}, 1.260-$ 19.703; $P=0.022$; day 3: $O R, 4.459 ; 95 \% C l, 1.162-17.121 ; P=0.029)$.

Conclusions: The outcomes of patients perceived as having non-beneficial admission were extremely poor. The intensivists' perception was important in predicting patients' outcomes and was more consistent with long-term prognosis than with immediate outcomes. The intensivists' role can be reflected in limited ICU resource utilization.

Key Words: critical care outcomes; critical illness; intensive care units; medical futility; patient admission; perception

\section{INTRODUCTION}

Advances in intensive care unit (ICU) treatment have led to improved survival of patients with critical illness. However, negative outcomes despite the provision of life-sustaining care can cause distress to patients and family members, inappropriate distribution of medical

\section{Original Article}

Received: March 5, 2021

Revised: July 27, 2021

Accepted: July 29, 2021

\section{Corresponding author}

Chae-Man Lim

Department of Pulmonary and

Critical Care Medicine, Asan Medical

Center, University of Ulsan College of

Medicine, 88 Olympic-ro 43-gil,

Songpa-gu, Seoul 05505, Korea

Tel: +82-2-3010-3135

Fax: +82-2-3010-4709

E-mail:cmlim@amc.seoul.kr
Copyright (c) 2021 The Korean Society of Critical Care Medicine

This is an Open Access article distributed under the terms of Creative Attributions Non-Commercial License (https:// creativecommons.org/li-censes/by-nc/4.0/) which permits unrestricted noncommercial use, distribution, and reproduction in any medium, provided the original work is properly cited. 
resources [1,2], burnout of ICU staff [3,4], and harm to other patients [5]. Thus, it is important for ICU physicians to distinguish which patient could benefit from ICU admission [6]. Knowing whose admission would be beneficial could help decide the priority of ICU admission, the level of treatment, and the distribution of medical resources.

In Asian countries, it is generally a taboo to discuss death with the individual directly involved. Particularly in the Confucianism cultural areas, including Korea, the notion of filial duties dissuades the family members of seriously ill patients from signing advance care directives, even if patients' conditions are irreversible or critical. Therefore, there has been scarce effort to investigate the appropriateness of ICU admission. We believe that the Korean society will probably face the issue of distributive justice of medical resources, considering increasing longevity, increasing compromised hosts, and restraint from government health insurance service.

Until recently, ICU treatment [7] was regarded as largely inappropriate when the patient has irreversible severe neurologic injuries or in cases in which physicians, nurses, and healthcare staff agree that the patient will not survive outside the acute care setting $[8,9]$. However, a concrete definition of beneficial or non-beneficial treatment/admission in the ICU does not exist. Therefore, the aim of this study was to evaluate the outcomes of critically ill patients according to the early perception of intensivists and to investigate whether the perception of ICU physicians can be a predictor of the prognosis of patients admitted to the ICU.

\section{MATERIALS AND METHODS}

\section{Ethics Statement}

This study was approved by the Institutional Review Board of Asan Medical Center (IRB No. 2014-0038) and waived the informed consents due to the nature of the study.

\section{Study Design}

This prospective observational study was conducted at a tertiary referral center located in Seoul, Korea. Its 28-bed semiclosed medical ICU is run by four full-time intensivists (all with more than 10 years of experience excluding the training period), along with four ICU fellows and six medical residents.

\section{Subjects}

All consecutive patients admitted to the medical ICU between February and April 2014 were included.

\section{KEY MESSAGES}

- The intensivists' perception of the appropriateness of intensive care unit (ICU) admission was consistent with the patients' ICU outcomes and long-term prognosis.

- Judgment according to the expertise of critical care specialists is meaningful for the evaluation of medical futility or non-beneficial admission.

- The role of intensivists can be reflected from the viewpoint of allocating limited resources at high cost in the ICU.

\section{Data Collection}

The following demographic and clinical data were collected from the patients: age, sex, underlying disease, reason for ICU admission, and route of ICU admission. The Acute Physiology and Chronic Health Evaluation (APACHE) II score was collected upon admission as the severity score. The perception of the intensivists toward ICU admission was categorized as non-beneficial admission, beneficial admission, or indeterminate state on the first day (day 1) and third day of ICU stay (day 3). The same physician who judged on day 1 was asked to judge the same patient's condition once again on day 3 , considering the treatment response within 48-72 hours after ICU admission. The intensivists were also asked regarding the anticipated duration of survival of each patient who was perceived as non-beneficially admitted.

\section{Non-beneficial Admission, Beneficial Admission, and Indeterminate State}

When the four critical care specialists who participated in the study wanted to make a judgment of non-beneficial admission, they were asked to make a judgment based on the following three circumstances and to select one of them as the reason for their perception: (1) serious underlying disease and irreversibility; (2) serious neurologic condition; and (3) imminent death within 7 days, which were defined as follows. First, "serious underlying disease and irreversibility" refers to end-stage disease with no further treatment available. For example, the "serious underlying disease" is stage IV lung cancer, and "irreversibility" refers to a condition in which there are no more drugs to use to improve lung cancer or a patient is no longer in a condition to be treated for a disease. Second, a "serious neurologic condition" is a condition judged to have difficulties in achieving recovery of meaningful consciousness 
in the future owing to serious neurological damage, such as severe brain injury. Third, "imminent death within 7 days" is defined as a condition in which death is predicted within a week because the current condition is very severe, and resuscitation is difficult even if intensive care is received. Beneficial admission was defined when the following three criteria were met: (1) a case that does not belong to any of the three abovementioned non-beneficial states, (2) when it is not expected that the patient would be dependent on life-sustaining treatment, and (3) when the patient is expected to recover after receiving intensive care and discharge from the ICU or the hospital. Meanwhile, when the patient's overall status remains at the boundary between non-beneficial and beneficial admissions, and it is difficult to determine either state, it was defined as "indeterminate" when the decision was withheld. The questionnaire used is provided as a Supplementary Material 1.

\section{Main Outcomes and Definitions}

The primary outcome was the ICU mortality rate. The secondary outcomes were the in-hospital and 6-month mortality rates and quality of life of the survivors 6 months after ICU discharge. The quality of life included the sensory-cognitive ability, physical activity, and degree of mobility. The level of sensory-cognitive ability was defined on the basis of the following four scores: 1, no ability; 2 , severely limited; 3 , mildly limited; and 4, no limitation. The level of physical activity was defined as follows: 1 , bedridden; 2 , able to sit; 3 , able to occasionally ambulate; and 4, able to often ambulate. The degree of mobility was defined as follows: 1 , no mobility; 2 , severely limited; 3 , mildly limited; and 4, no limitation.

\section{Statistical Analysis}

Continuous variables are reported as medians (interquartile range [IQR], 25\%-75\%) or means ( \pm standard deviations) and categorical variables as numbers (percentages). Statistical analysis was performed using IBM SPSS ver. 25.0 (IBM Corp., Armonk, NY, USA). To assess the differences among the groups, we compared the data using the t-test or Mann-Whitney test for continuous variables and the chi-square or Fisher's exact test for categorical variables. Analysis of variance was used to compare the continuous variables among the three groups. A univariate analysis was performed with each variable using binary logistic regression. A multivariate analysis was performed with a backward, stepwise, logistic regression model. Variables that yielded P-values $<0.05$ in the univariate analysis were included in the multivariate analysis.

\section{RESULTS}

\section{Patient Characteristics}

A total of 210 patients were enrolled in this study. Their mean age was $64 \pm 14$ years, and 139 patients $(66 \%)$ were men. One third of the patients (34\%) had solid tumor malignancy or hematologic malignancy. Acute respiratory failure was the most common (52\%) reason for ICU admission. The mean APACHE II score at ICU admission was $25 \pm 9$. Transfer from the general ward was the most common route of ICU admission (58\%). Most of the patients, except for two, had consented to all possible treatments before admission to the ICU (Table 1).

\section{Perceptions of the Intensivists Regarding Patient Admission to the ICU on Day 1 and Day 3}

On day 1, 22 patients (10\%) were perceived as having non-beneficial admission; 166 (79\%), beneficial admission; and $22(10 \%)$, indeterminate state (Table 2). On day 3, 202 of the 210 patients remained in the ICU. The eight patients were discharged between day 1 and day 3; three died, while five showed improved conditions and were transferred to the general ward. On day 3 , the intensivists perceived 23 (11\%) of the 202 patients as having non-beneficial admission; 159 (79\%), beneficial admission; and 21 (10\%), indeterminate state. The most common reason for the perception of non-beneficial admission was serious and irreversible underlying disease. The original perceptions on day 1 for $90 \%$ of the patients were sustained on day 3 . For $20(10 \%)$ patients, the perceptions changed. The perceptions for six (3\%) of these patients changed to the contrary perception between day 1 and day 3 (from non-beneficial to beneficial or vice versa). The characteristics of these patients and clinical courses during the 3 days are described in Supplementary Table 1.

\section{Outcomes}

Among the total of 210 patients, the ICU mortality rate was $30 \%$, and the in-hospital and 6-month mortality rates were $44 \%$ and $57 \%$, respectively (Figure 1). Among the 22 patients who were perceived as having non-beneficial admission on day $1,13(59 \%)$ died in the ICU. Their in-hospital mortality rate increased to $82 \%$. In this group, there were no survivors at the 6-month follow-up. In the beneficial admission group, the ICU, in-hospital, and 6-month mortality rates were $23 \%, 34 \%$, and $48 \%$, respectively; in the indeterminate state group, the mortality rates were $59 \%, 82 \%$, and $82 \%$, respectively. Even according to the day 3 perceptions, the non-beneficial admission 
Table 1. Baseline characteristics

\begin{tabular}{|c|c|c|c|c|c|}
\hline Characteristics & $\begin{array}{l}\text { All patients } \\
(n=210)\end{array}$ & $\begin{array}{c}\text { Non-beneficial } \\
\text { admission }(n=22)\end{array}$ & $\begin{array}{l}\text { Beneficial admission } \\
\quad(n=166)\end{array}$ & $\begin{array}{l}\text { Indeterminate state } \\
\qquad(\mathrm{n}=22)\end{array}$ & P-value \\
\hline Age (yr) & $64 \pm 14$ & $63 \pm 14$ & $64 \pm 14$ & $68 \pm 15$ & 0.474 \\
\hline Male & $139(66)$ & $15(68)$ & $112(68)$ & $12(55)$ & 0.474 \\
\hline \multicolumn{6}{|l|}{ Underlying disease } \\
\hline $\mathrm{DM}$ & $66(31)$ & $8(36)$ & $50(30)$ & $8(36)$ & 0.730 \\
\hline Hypertension & $91(43)$ & $7(32)$ & $72(43)$ & $12(55)$ & 0.314 \\
\hline Hepatitis & $20(10)$ & 0 & $16(11)$ & $1(5)$ & 0.201 \\
\hline Pulmonary tuberculosis & $32(15)$ & $3(14)$ & $24(15)$ & $5(23)$ & 0.570 \\
\hline Malignancy & $71(34)$ & $11(50)$ & $54(33)$ & $6(27)$ & 0.210 \\
\hline Hematologic & $24(11)$ & $4(18)$ & $19(11)$ & $1(5)$ & 0.350 \\
\hline Solid tumor & $47(22)$ & $7(32)$ & $35(21)$ & $5(23)$ & 0.457 \\
\hline Liver cirrhosis & $17(8)$ & $3(14)$ & $12(7)$ & $2(9)$ & 0.526 \\
\hline COPD & $14(7)$ & 0 & $13(8)$ & $1(5)$ & 0.602 \\
\hline ESRD & $9(4)$ & $1(5)$ & $6(4)$ & 2 (9) & 0.285 \\
\hline Others & $2(1)$ & 0 & $1(1)$ & $1(5)$ & 0.376 \\
\hline \multicolumn{6}{|l|}{ Reason for ICU admission } \\
\hline Acute respiratory failure & $109(52)$ & $10(46)$ & $83(50)$ & $16(73)$ & 0.109 \\
\hline Sepsis/septic shock & $38(18)$ & $4(18)$ & $32(20)$ & $2(9)$ & 0.615 \\
\hline Postoperative care & $16(8)$ & 0 & $16(10)$ & 0 & 0.119 \\
\hline Acute liver failure & $13(6)$ & $1(5)$ & $10(6)$ & $2(9)$ & 0.866 \\
\hline Hemorrhagic shock & $11(5)$ & $2(9)$ & $9(5)$ & 0 & 0.448 \\
\hline Heart failure/ACS & $5(2)$ & 0 & $4(2)$ & $1(5)$ & 0.695 \\
\hline Acute renal failure & $5(2)$ & 0 & $4(2)$ & $1(5)$ & 0.695 \\
\hline CPCR survivor & $5(2)$ & $4(18)$ & $1(1)$ & 0 & 0.001 \\
\hline For procedure & $4(2)$ & 0 & $4(2)$ & 0 & 1.000 \\
\hline Acute cerebral hemorrhage/stroke & $2(1)$ & $1(5)$ & $1(1)$ & 0 & 0.376 \\
\hline For surgery & $1(1)$ & 0 & $1(1)$ & 0 & 0.119 \\
\hline Others & $1(1)$ & 0 & $1(1)$ & 0 & 1.000 \\
\hline APACHE II score at ICU admission & $25 \pm 9$ & $30 \pm 8$ & $26 \pm 9$ & $29 \pm 7$ & $<0.001^{\mathrm{a}}$ \\
\hline \multicolumn{6}{|l|}{ Route of ICU admission } \\
\hline General ward & $122(58)$ & $12(55)$ & $97(58)$ & $13(59)$ & 0.968 \\
\hline Emergency room & $79(38)$ & $10(25)$ & $62(37)$ & 7 (32) & 0.639 \\
\hline Transfer from other hospital & $9(4)$ & 0 & $7(4)$ & $2(9)$ & 0.437 \\
\hline \multicolumn{6}{|l|}{ DNR status } \\
\hline Before ICU admission & $2(1)$ & 0 & $1(1)$ & $1(1)$ & 0.179 \\
\hline During ICU stay & $61(29)$ & $12(55)$ & $35(21)$ & $14(64)$ & $<0.001$ \\
\hline During the entire hospitalization & $74(35)$ & $12(55)$ & $47(28)$ & 15 (68) & $<0.001$ \\
\hline
\end{tabular}

Values are presented as mean \pm standard deviation or number $(\%)$.

DM: diabetes mellitus; COPD: chronic obstructive pulmonary disease; ESRD: end-stage renal disease; ICU: intensive care unit; ACS: acute coronary syndrome; CPCR: cardiopulmonary cerebral resuscitation; APACHE: Acute Physiology and Chronic Health Evaluation; DNR: do-not-resuscitate.

${ }^{a}$ Non-beneficial admission group versus beneficial admission group, $\mathrm{P}=0.001$; beneficial admission group versus indeterminate state group, $\mathrm{P}=0.011$; nonbeneficial admission group versus indeterminate state group, $\mathrm{P}=0.534$.

group and the indeterminate state group showed high ICU, in-hospital, and 6-month mortality rates.

\section{Expected and Actual Survival Times of the Patients} Perceived as Having Non-beneficial Admission

The anticipated survival time of the non-beneficial admission 
group was $<4$ weeks for $73 \%$ of the patients and 4 weeks to 6 months for $27 \%$ of the patients. The actual survival time was only 12 days (IQR, 4-53 days). For $46 \%$ of the patients, the anticipations of the intensivists were correct with regard to the actual survival time. In cases with discrepancy, the actual survival time was longer than the anticipated survival time. The differences between the two survival times were mostly within 1 week to 1 month (Supplementary Table 2).

\section{Quality of Life 6 Months after ICU Discharge of the 6-Month Survivors}

When the quality of life of the 6-month survivors after dis-

Table 2. Perception of the intensivists on patient admission to the ICU on day 1 and day 3

\begin{tabular}{lcc}
\hline Characteristics & Day 1 & Day 3 \\
\hline Perception of the intensivists & $(n=210)$ & $\left(n=202^{a}\right)$ \\
Non-beneficial admission & $22(10)$ & $22(11)$ \\
Beneficial admission & $166(79)$ & $159(79)$ \\
Indeterminate state & $22(10)$ & $21(10)$ \\
Reason for perception as non-beneficial admission & $(n=22)$ & $(n=22)$ \\
Serious underlying disease and irreversibility & $18(82)$ & $19(86)$ \\
Serious neurologic condition & $2(9)$ & $3(14)$ \\
Imminent death within 7 days & $2(9)$ & 0 \\
\hline
\end{tabular}

Values are presented as number (\%).

ICU: intensive care unit.

${ }^{\mathrm{a}}$ On day 3, 202 of the 210 patients remained in the ICU. charge from the ICU was compared with that at the time of admission to the ICU, the sensory-cognitive ability, physical

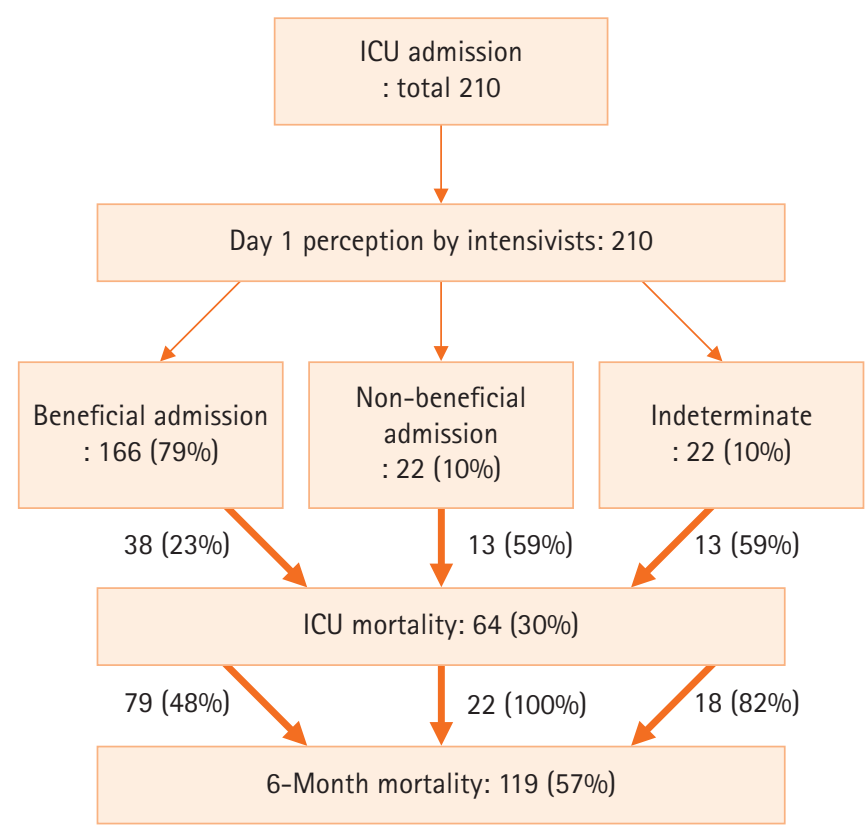

Figure 1. Outcomes of patients according to the perception of intensivists on the appropriateness of intensive care unit (ICU) admission. Among the patients who were perceived as having non-beneficial admission by intensivists or for whom it was difficult for the intensivists to decide whether their ICU admission was beneficial (indeterminate) on ICU day 1 , more than half died in the ICU, while most of them died after 6 months.

Table 3. Quality of life 6 months after ICU discharge of the 6-month survivors

\begin{tabular}{|c|c|c|c|}
\hline Variable for quality of life & ICU admission $(n=91)$ & 6 Months after ICU discharge $(n=87)^{a}$ & Interval improvement ${ }^{\mathrm{a}}$ \\
\hline Sensory/cognitive ability & & & $37(43)$ \\
\hline No ability & $3(3)$ & 0 & \\
\hline Severely limited & $24(26)$ & $5(6)$ & \\
\hline Mildly limited & $22(24)$ & $9(10)$ & \\
\hline No limitation & $42(46)$ & $73(84)$ & \\
\hline Physical activity & & & $75(86)$ \\
\hline Bedridden & $53(58)$ & $4(4)$ & \\
\hline Able to sit up & $34(37)$ & $22(24)$ & \\
\hline Able to occasionally ambulate & $2(2)$ & $23(25)$ & \\
\hline Able to often ambulate & $2(2)$ & $38(42)$ & \\
\hline Degree of mobility & & & $61(70)$ \\
\hline No mobility & $10(11)$ & $2(2)$ & \\
\hline Severely limited & $47(52)$ & $12(13)$ & \\
\hline Mildly limited & $27(30)$ & $30(33)$ & \\
\hline No limitation & 7 (8) & $43(47)$ & \\
\hline
\end{tabular}

Values are presented as number (\%).

ICU: intensive care unit.

${ }^{a}$ Four patients missing. 
activity, and degree of mobility showed a tendency to improve in most patients. In particular, the physical activity and degree of mobility showed significant improvements in the meantime in $86 \%$ and $70 \%$ of the patients, respectively (Table 3). Notably, $46 \%$ of the 6 -month survivors had no impairment in the sensory/cognitive ability at the time of admission to the ICU; $84 \%$ of the patients had no disability at all 6 months after discharge.

\section{Perceptions of the Intensivists as a Predictor for ICU and 6-Month Mortalities}

To evaluate the predictors of survival from ICU and 6-month mortalities for all patients admitted to the ICU, we performed univariate and multivariate analyses. The comparisons of the characteristics of the survivors and non-survivors in each group are presented in Table 4 . In the multivariate analysis, the day 3 perception of the intensivists as non-beneficial admission or indeterminate state (odds ratio [OR], 4.049; 95\% confidence interval $[\mathrm{CI}], 1.892-8.664 ; \mathrm{P}<0.001)$ and APACHE II score at ICU admission (OR, 1.074; 95\% CI, 1.031-1.118; $\mathrm{P}<0.001$ ) were found to be the significant predictive factors of ICU mortality (Table 5). Meanwhile, the day 1 perception of the intensivists as non-beneficial admission or indeterminate state (OR, 4.983; 95\% CI, 1.260-19.703; $\mathrm{P}=0.022$ ), day 3 perception of the intensivists as non-beneficial admission or indeterminate state (OR, 4.459; 95\% CI, 1.162-17.121; $\mathrm{P}=0.029$ ), solid tumor malignancy (OR, 3.411; 95\% CI, 1.480-7.861; $\mathrm{P}=0.004)$, and male sex (OR, 2.616; 95\% CI, 1.289-5.311; $\mathrm{P}=0.008$ ) (Table 5) were found to be the significant predictive factors of 6 -month mortality.

\section{DISCUSSION}

This study found that the perceptions of the intensivists toward the appropriateness of ICU admission were consistent with the prognosis of the critically ill patients. Thus, the perception of the intensivists was found as a significant predictor of not only ICU outcomes (short-term prognosis) but also 6-month outcomes (long-term prognosis).

In this series of patients, $10 \%$ of the ICU admissions were perceived as non-beneficial, $80 \%$ as beneficial, and $10 \%$ as indeterminate. The survival rate at the time of ICU discharge between the non-beneficial and beneficial admission groups was significantly different ( $36 \%$ vs. $78 \%$ ), which further diverged at the 6 -month follow-up ( $0 \%$ vs. $52 \%$ ). Thus, the outcomes of the patients perceived as having non-beneficial admission were extremely poor. The main characteristics of this group of patients were a high APACHE II score, a high rate of malignancy, and a significantly higher proportion of cardiopulmonary cerebral resuscitation survivors than those of other groups. The ICU and 6-month survival rates of the patients who were perceived as having an indeterminate state were quite similar to those of the patients who were perceived as having non-beneficial admission. They showed similar characteristics to those of the beneficial admission group in terms of the distribution of comorbidities and to those of the non-beneficial admission group in terms of the initial severity. Meanwhile, most (96\%) of the 6-month survivors included those whom the intensivists perceived as having beneficial admission on day 1 . The quality of life of the 6-month survivors significantly improved over time, compared with that at ICU admission.

This study is unique from previous studies $[1,3,10,11]$ in that the perceptions of the critical care physicians were evaluated on the first day of ICU admission and at another time point (day 3) after the very critical resuscitation period in the ICU. Interestingly, 9 out of 10 patients were classified under the same perception on day 3 as on day 1 . A few non-beneficial admission perceptions on day 1 were changed to beneficial admission perceptions on day 3 when there was a significant change in the treatment plan or considerable improvement of acute disease. Meanwhile, a few beneficial admission perceptions were changed to non-beneficial admission perceptions when there was a progressive physiologic deterioration, such as the development of multi-organ failure. This switch in perception in our study was in agreement with that in a previous study that showed that the deterioration of acute physiologic state on the third day helped identify non-beneficial care better than that on the first day [12].

Critical care physicians often encounter patients of the indeterminate state group. Thus, it justifies the need for a trial of therapy $[6,12]$. In our study, the overall outcomes of the indeterminate state group were as poor as those of the non-beneficial admission group. Those perceived as having an indeterminate state on day 1 but a non-beneficial or beneficial admission on day 3 showed outcomes in agreement with the day 3 perceptions. However, those perceived as having beneficial or non-beneficial admission on day 1 but an indeterminate state on day 3 showed outcomes similar to the corresponding original outcomes on day 1 . These findings suggest that critically ill patients with indeterminate prospects at the outset of ICU treatment may warrant therapeutic trial of 3 days to determine the short-term and long-term prognoses with better accuracy. In cases where physicians cannot still make a judgment after the therapeutic trial, the chances for 
Table 4. Comparison of the characteristics of the patients according to ICU and 6-month mortalities

\begin{tabular}{|c|c|c|c|c|c|c|c|}
\hline \multirow[b]{2}{*}{ Characteristics } & \multicolumn{3}{|c|}{ ICU outcome } & \multirow[b]{2}{*}{ P-value } & \multicolumn{2}{|c|}{ 6-month outcome } & \multirow[b]{2}{*}{ P-value } \\
\hline & $\begin{array}{c}\text { All patients } \\
(n=210)\end{array}$ & $\begin{array}{l}\text { Survivor } \\
(n=146)\end{array}$ & $\begin{array}{c}\text { Non-survivor } \\
(n=64)\end{array}$ & & $\begin{array}{c}\text { Survivor } \\
(n=91)\end{array}$ & $\begin{array}{c}\text { Non-survivor } \\
(n=119)\end{array}$ & \\
\hline Age (yr) & $64 \pm 14$ & $64 \pm 15$ & $66 \pm 13$ & 0.31 & $64 \pm 16$ & $65 \pm 13$ & 0.809 \\
\hline Male & $139(66)$ & $96(66)$ & $43(67)$ & 0.84 & $52(57)$ & 87 (73) & 0.015 \\
\hline \multicolumn{8}{|l|}{ Underlying disease } \\
\hline DM & $66(31)$ & $45(31)$ & $21(33)$ & 0.775 & $31(34)$ & $35(29)$ & 0.155 \\
\hline Hypertension & $91(43)$ & $66(45)$ & $25(39)$ & 0.408 & $41(45)$ & $50(42)$ & 0.660 \\
\hline Hepatitis & $20(10)$ & $11(8)$ & $9(14)$ & 0.138 & 7 (8) & $13(11)$ & 0.429 \\
\hline Pulmonary tuberculosis & $32(15)$ & $19(13)$ & $13(20)$ & 0.176 & $10(11)$ & $22(19)$ & 0.134 \\
\hline Malignancy & $71(34)$ & $49(34)$ & $22(34)$ & 0.909 & $18(20)$ & $53(45)$ & $<0.001$ \\
\hline Hematologic & $24(11)$ & $15(10)$ & $9(14)$ & 0.427 & 7 (8) & $17(14)$ & 0.137 \\
\hline Solid tumor & $47(22)$ & $34(23)$ & $13(20)$ & 0.634 & $11(12)$ & $36(30)$ & 0.002 \\
\hline Liver cirrhosis & $17(8)$ & $10(7)$ & $7(11)$ & 0.317 & $3(3)$ & $14(12)$ & 0.026 \\
\hline COPD & $14(7)$ & $12(8)$ & $2(3)$ & 0.236 & $9(10)$ & $5(4)$ & 0.102 \\
\hline ESRD & $9(4)$ & $7(5)$ & $2(3)$ & 0.725 & $7(8)$ & $2(2)$ & 0.042 \\
\hline Others & $2(1)$ & $1(1)$ & $1(2)$ & 0.518 & 0 & $2(2)$ & 0.507 \\
\hline \multicolumn{8}{|l|}{ Reason for ICU admission } \\
\hline Acute respiratory failure & 109 (52) & $75(51)$ & $34(53)$ & 0.815 & $50(55)$ & $59(50)$ & 0.441 \\
\hline Sepsis/septic shock & $38(18)$ & $29(20)$ & $9(14)$ & 0.315 & $16(18)$ & $22(19)$ & 0.866 \\
\hline Postoperative care & $16(8)$ & $16(11)$ & 0 & 0.003 & $10(11)$ & $6(5)$ & 0.107 \\
\hline Acute liver failure & $13(6)$ & $8(6)$ & $5(8)$ & 0.541 & $5(6)$ & $8(7)$ & 0.714 \\
\hline Hemorrhagic shock & $11(5)$ & $7(5)$ & $4(6)$ & 0.739 & $4(4)$ & $7(6)$ & 0.760 \\
\hline Heart failure/ACS & $5(2)$ & $1(1)$ & $4(6)$ & 0.031 & 0 & $5(4)$ & 0.071 \\
\hline Acute renal failure & $5(2)$ & $3(2)$ & $2(3)$ & 0.642 & $3(3)$ & $2(2)$ & 0.654 \\
\hline CPCR survivor & $5(2)$ & $1(1)$ & $4(6)$ & 0.031 & $0(0)$ & $5(4)$ & 0.071 \\
\hline For procedure & $5(2)$ & $4(3)$ & $1(2)$ & 1.000 & $2(2)$ & $3(3)$ & 1.000 \\
\hline Acute CVA & $2(1)$ & $1(1)$ & $1(2)$ & 0.518 & 0 & $2(2)$ & 0.507 \\
\hline For surgery & $16(8)$ & $16(11)$ & 0 & 0.003 & $10(11)$ & $6(5)$ & 0.290 \\
\hline Others & $1(1)$ & $1(1)$ & 0 & 1.000 & $1(1)$ & 0 & 0.433 \\
\hline APACHE II score at ICU admission & $25 \pm 9$ & $23 \pm 8$ & $29 \pm 9$ & $<0.001$ & $23 \pm 9$ & $26 \pm 9$ & 0.027 \\
\hline \multicolumn{8}{|l|}{ Route of ICU admission } \\
\hline GW & $122(58)$ & $83(57)$ & $39(61)$ & 0.580 & $47(52)$ & $75(63)$ & 0.098 \\
\hline$E R$ & 79 (38) & $55(38)$ & $24(38)$ & 0.981 & $40(44)$ & 39 (33) & 0.097 \\
\hline Transfer from other hospital & $9(4)$ & $8(6)$ & $1(2)$ & 0.282 & $4(4)$ & $5(4)$ & 1.000 \\
\hline \multicolumn{8}{|l|}{ Day 1 perception of the intensivists } \\
\hline Non-beneficial admission or indeterminate state & $44(21)$ & $18(12)$ & $26(41)$ & $<0.001$ & $4(4)$ & $40(34)$ & $<0.001$ \\
\hline \multicolumn{8}{|l|}{ Day 3 perception of the intensivists } \\
\hline Non-beneficial admission or indeterminate state & $43(20)$ & $17(12)$ & $26(41)$ & $<0.001$ & $4(4)$ & 39 (33) & $<0.001$ \\
\hline
\end{tabular}

Values are presented as mean \pm standard deviation or number (\%).

ICU: intensive care unit; DM: diabetes mellitus; COPD: chronic obstructive pulmonary disease; ESRD: end-stage renal disease; ACS: acute coronary syndrome;

CPCR: cardiopulmonary cerebral resuscitation; CVA: cerebrovascular accident (hemorrhage or stroke); APACHE II: Acute Physiology and Chronic Health Evaluation II; GW: general ward; ER: emergency room.

meaningful outcomes are thought to be poor, as in those of the non-beneficial admission group on day 1 .

The intensivists in our study were asked to provide an es- timate of the anticipated survival time of the non-beneficial admission group. They expected those patients to survive for as long as 1 to 6 months. However, no intensivist expected a 


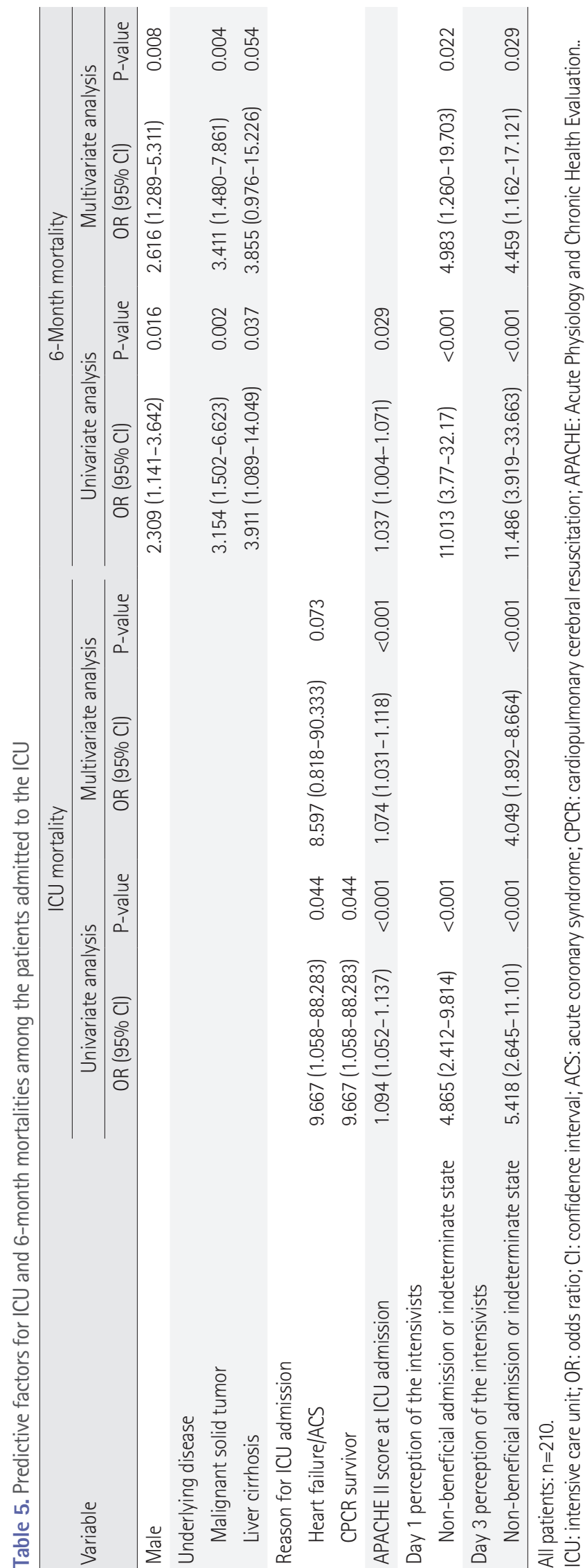

survival time of over 6 months. This consequently suggests that intensivists, at least in our study, perceive that beneficial admission should ensure at least a 6-month survival. In this regard, the current statement regarding the appropriate goal of ICU care [8], defining appropriateness simply as survival outside acute care settings, may not be precise enough for individual situations. It also indicates that the perceptions of intensivists toward the appropriateness of ICU admission are more consistent with the long-term prognosis than with the immediate outcomes of ICU admission. Recent studies have also confirmed that ICU physicians predict a patient's prognosis with a longer view [13].

The current scoring system for critically ill patients provides information on the short-term mortality rate but has limitations in predicting the patient's condition in terms of longterm prognosis and quality of life issues [14-16]. This is where the role of critical care physicians arise. In this study, when the intensivists judged the futility of ICU admission based on their expertise, their perceptions were found to be in good agreement with not only the short-term but also the long-term prognosis. These results suggest the possibility that intensivists' perceptions can supplement the limitations of the current scoring system. In other words, the patient's prognosis should not be viewed solely based on physiological values, such as the APACHE II score; instead, the intensivist's perception on futility should be considered as important. This is because most ICU physicians inform the family regarding the patient's prognosis largely based on their professional perception and experience rather than applying a specific scoring system. The implications of our study are also consistent with existing views [17]. Meanwhile, considering an example in which human perception can serve as an objective indicator, such as the intensivist's perception, when evaluating dyspnea, the patient's subjective perception is used as an objective tool, including the New York Heart Association functional classification [18] and Medical Research Council dyspnea scale [19,20]. Further, just as the perception of pain is used as a tool for pain scales [21], the perception of intensivists can also be accepted as an important indicator for evaluating the prognosis of patients.

This study has several limitations. First, the study was performed at the medical ICU of a single center, which precludes the generalization of the findings. In particular, the number of patients perceived as having non-beneficial admission was too small to draw a firm conclusion on their characteristics. Second, because the intensivists participating in the study have been practicing for more than 10 years, the perceptions of in- 
tensivists of less expertise and the resultant findings may differ from those of our study. In this context, since one patient was judged by only one physician, how consistent the perceptions for the patient among the intensivists were not investigated. Finally, the blinding method was not applied in this study, and the study participants judged and participated in the actual treatment decision. Therefore, the possibility of affecting the patient's prognosis cannot be excluded, though we attempted to minimize the impact by providing intensive care for the first 3 days with all possibilities open.

In conclusion, this study indicates that the intensivist's perception toward the appropriateness of ICU admission is quite consistent with the actual prognosis of the patient, especially the long-term prognosis. The findings suggest that the intensivist's perception on medical futility can compensate the limitations of the current scoring system for critically ill patients and therefore be an important tool in creating a new prognostic model that can predict patients' long-term outcomes. The role of critical care physicians can be reflected in the utilization of limited ICU resources.

\section{CONFLICT OF INTEREST}

No potential conflict of interest relevant to this article was reported.

\section{ORCID}

$\begin{array}{ll}\text { Youjin Chang } & \text { https://orcid.org/0000-0002-4838-466X } \\ \text { Kyoung Ran Kim } & \text { https://orcid.org/0000-0002-5123-4283 } \\ \text { Jin Won Huh } & \text { https://orcid.org/0000-0002-3449-0461 } \\ \text { Sang-Bum Hong } & \text { https://orcid.org/0000-0003-2737-7695 } \\ \text { Younsuck Koh } & \text { https://orcid.org/0000-0001-5066-2027 } \\ \text { Chae-Man Lim } & \text { https://orcid.org/0000-0001-5400-6588 }\end{array}$

\section{AUTHOR CONTRIBUTIONS}

Conceptualization: CML. Data curation: YC, KRK. Formal analysis: YC. Methodology: CML, YC. Project administration: CML, YC, KRK. Visualization: CML, YC. Writing-original draft: CML, YC. Writing-review \& editing: YC, CML, YK, JWH, SBH.

\section{SUPPLEMENTARY MATERIALS}

Supplementary materials can be found via https://doi.org/10. 4266/acc.2021.00283.

\section{REFERENCES}

1. Huynh TN, Kleerup EC, Raj PP, Wenger NS. The opportunity cost of futile treatment in the ICU. Crit Care Med 2014;42:197782.

2. Carter HE, Winch S, Barnett AG, Parker M, Gallois C, Willmott L, et al. Incidence, duration and cost of futile treatment in end-oflife hospital admissions to three Australian public-sector tertiary hospitals: a retrospective multicentre cohort study. BMJ Open 2017;7:e017661.

3. Piers RD, Azoulay E, Ricou B, Dekeyser Ganz F, Decruyenaere J, Max A, et al. Perceptions of appropriateness of care among European and Israeli intensive care unit nurses and physicians. JAMA 2011;306:2694-703.

4. Schwarzkopf D, Rüddel H, Thomas-Rüddel DO, Felfe J, Poidinger B, Matthäus-Krämer CT, et al. Perceived nonbeneficial treatment of patients, burnout, and intention to leave the job among ICU nurses and junior and senior physicians. Crit Care Med 2017;45:e265-73.

5. Niederman MS, Berger JT. The delivery of futile care is harmful to other patients. Crit Care Med 2010;38(10 Suppl):S518-22.

6. Angus DC, Truog RD. Toward better ICU Use at the end of life. JAMA 2016;315:255-6.

7. Nates JL, Nunnally M, Kleinpell R, Blosser S, Goldner J, Birriel B, et al. ICU admission, discharge, and triage guidelines: a framework to enhance clinical operations, development of institutional policies, and further research. Crit Care Med 2016;44: 1553-602.

8. Kon AA, Shepard EK, Sederstrom NO, Swoboda SM, Marshall MF, Birriel B, et al. Defining futile and potentially inappropriate interventions: a policy statement from the Society of Critical Care Medicine Ethics Committee. Crit Care Med 2016;44:176974.

9. Downar J, You JJ, Bagshaw SM, Golan E, Lamontagne F, Burns K, et al. Nonbeneficial treatment Canada: definitions, causes, and potential solutions from the perspective of healthcare practitioners. Crit Care Med 2015;43:270-81.

10. Huynh TN, Kleerup EC, Wiley JF, Savitsky TD, Guse D, Garber BJ, et al. The frequency and cost of treatment perceived to be futile in critical care. JAMA Intern Med 2013;173:1887-94.

11. Palda VA, Bowman KW, McLean RF, Chapman MG. "Futile" care: do we provide it? Why? A semistructured, Canada-wide survey of intensive care unit doctors and nurses. J Crit Care 2005;20:207-13.

12. Afessa B, Keegan MT, Mohammad Z, Finkielman JD, Peters SG. Identifying potentially ineffective care in the sickest critically ill 
patients on the third ICU day. Chest 2004;126:1905-9.

13. Detsky ME, Harhay MO, Bayard DF, Delman AM, Buehler AE, Kent SA, et al. discriminative accuracy of physician and nurse predictions for survival and functional outcomes 6 months after an ICU admission. JAMA 2017;317:2187-95.

14. Herridge MS. Prognostication and intensive care unit outcome: the evolving role of scoring systems. Clin Chest Med 2003;24:751-62.

15. Vincent JL, Moreno R. Clinical review: scoring systems in the critically ill. Crit Care 2010;14:207.

16. Cooke CR. The siren song of simple tools that predict mortality. Respir Care 2011;56:533-5.

17. Sinuff T, Adhikari NK, Cook DJ, Schünemann HJ, Griffith LE,
Rocker G, et al. Mortality predictions in the intensive care unit: comparing physicians with scoring systems. Crit Care Med 2006;34:878-85.

18. Dolgin M, New York Heart Association, Criteria Committee. Nomenclature and criteria for diagnosis of diseases of the heart and great vessels. 9th ed. Boston (MA): Little Brown \& Co; 1994.

19. Fletcher CM. The clinical diagnosis of pulmonary emphysema: an experimental study. Proc R Soc Med 1952;45:577-84.

20. Fletcher CM, Elmes PC, Fairbairn AS, Wood CH. The significance of respiratory symptoms and the diagnosis of chronic bronchitis in a working population. Br Med J 1959;2:257-66.

21. McCaffery M, Beebe A. Pain: clinical manual for nursing practice. St. Louis (MO): Mosby; 1989. 
Supplementary Material 1. Questionnaire on the perception of intensivists on the appropriateness of intensive care unit admission

\section{Term Definitions}

1) Non-beneficial admission is defined when one of the following three conditions is satisfied: (1) serious underlying disease and irreversibility; (2) serious neurologic condition; and (3) imminent death within 7 days, which are defined as follows. First, "serious underlying disease and irreversibility" refers to end-stage disease with no further treatment available. For example, the "serious underlying disease" is stage IV lung cancer, and "irreversibility" refers to a condition in which there are no more drugs to use to improve lung cancer or a patient is no longer in a condition to be treated for a disease. Second, a "serious neurologic condition" is a condition evaluated to have difficulties in achieving recovery of meaningful consciousness in the future owing to serious neurological damage, such as severe brain injury. Third, "imminent death within 7 days" is defined as a condition in which death is predicted within a week because the current condition is very severe, and resuscitation is difficult even if intensive care is received.

2) Beneficial admission is defined when one of the following three conditions is satisfied: (1) a case that does not belong to any of the three abovementioned non-beneficial states, (2) when it is not expected that the patient would be dependent on life-sustaining treatment, and (3) when the patient is expected to recover after receiving intensive care and discharge from the intensive care unit (ICU) or the hospital.

3) Indeterminate state is defined when the decision is withheld when a patient's overall status remains at the boundary between non-beneficial and beneficial admissions and it is difficult to determine either state.

\section{Day 1 (ICU admission)}

Question 1) According to the abovementioned definitions, do you think this patient's ICU admission will be beneficial or non-beneficial? If it is difficult to decide based on the current state alone, please select indeterminate.

1) Non-beneficial

2) Beneficial

3) Indeterminate

Question 2) If you perceived it as non-beneficial, why did you judge it that way?

1) Serious underlying disease and its irreversibility

2) Serious neurologic condition

3) Imminent death within 7 days

\section{Day 3 (48-72 hours after ICU admission)}

Question 1) According to the abovementioned definitions, do you think this patient's ICU admission will be beneficial or non-beneficial? If it is difficult to decide based on the current state alone, please select indeterminate.
1) Non-beneficial
2) Beneficial
3) Indeterminate

Question 2) If you perceived it as non-beneficial, why did you judge it that way?

1) Serious underlying disease and its irreversibility

2) Serious neurologic condition

3) Imminent death within 7 days 
Supplementary Table 1. Demographics and clinical courses of the patients with changes in perception between day 1 and day 3

\begin{tabular}{|c|c|c|c|c|c|c|}
\hline Day 1 & Day 3 & No. & $\begin{array}{l}\text { Sex/age } \\
(y r)\end{array}$ & Underlying disease & Reason for ICU admission & $\begin{array}{l}\text { ICU course between } \\
\text { day } 1 \text { and day } 3 \\
\end{array}$ \\
\hline \multirow[t]{2}{*}{$\begin{array}{l}\text { Non-beneficial } \\
\text { admission }\end{array}$} & $\begin{array}{l}\text { Beneficial } \\
\text { admission }\end{array}$ & 1 & $\mathrm{M} / 58$ & $\begin{array}{l}\text { Amyopathic dermatomyositis- } \\
\text { related organizing pneumonia } \\
\text { Bronchiectasis }\end{array}$ & $\begin{array}{l}\text { Acute respiratory failure } d / t \\
\text { pneumonia with } R V \text { failure } \\
\text { Septic shock d/t perianal } \\
\text { abscess }\end{array}$ & $\begin{array}{l}\text { Venous-arterial ECMO d/t } \\
\text { deteriorated RV failure } \\
\rightarrow \text { considering lung } \\
\text { transplantation }\end{array}$ \\
\hline & & 2 & $\mathrm{M} / 73$ & $\begin{array}{l}\text { AML with persistent disease state } \\
\text { after study chemotherapy }\end{array}$ & & $\begin{array}{l}\text { Clinically improving state with } \\
\text { reduced dose of vasopressor }\end{array}$ \\
\hline & & 3 & $\mathrm{M} / 73$ & $\begin{array}{l}\text { AML, M0 } \\
\text { s/p 2nd chemotherapy } 5 \text { days ago } \\
\text { ECOG PS } 0 \\
\text { COPD } \\
\text { Hypertension } \\
\text { Gout }\end{array}$ & $\begin{array}{l}\text { Acute respiratory failure with } \\
\text { septic shock d/t aspiration } \\
\text { pneumonia with colitis } \\
\text { during chemotherapy }\end{array}$ & $\begin{array}{l}\text { Progressive septic shock } \\
\text { Severe hypoxemia } \\
\text { Severe intra-abdominal } \\
\text { hypertension } \\
\text { Multi-organ failure }\end{array}$ \\
\hline & & 4 & $\mathrm{M} / 80$ & $\begin{array}{l}\text { COPD } \\
\text { Atrial fibrillation } \\
\text { Hypertension } \\
\text { History of pulmonary tuberculosis } \\
\text { History of CABG at } 10 \text { years ago }\end{array}$ & $\begin{array}{l}\text { Acute respiratory failure d/ } \\
\text { t pneumonia with COPD } \\
\text { aggravation }\end{array}$ & $\begin{array}{l}\text { Deteriorated lung compliance } \\
\text { Suspected obstructive } \\
\text { pneumonitis d/t lung cancer } \\
\text { (higher possibility of the } \\
\text { presence of lung cancer) }\end{array}$ \\
\hline
\end{tabular}

ICU: intensive care unit; RV: right ventricle; ECMO: extracorporeal membrane oxygenation; AML: acute myeloid leukemia; ECOG PS: Eastern Cooperative Oncology Group performance status; GI: gastrointestinal; SVC: superior vena cava; COPD: chronic obstructive disease; CABG: coronary artery bypass graft. 
Supplementary Table 2. Expected and actual survival times of the patients perceived as having non-beneficial admission

\begin{tabular}{lc}
\hline Characteristics & Intensivists $(n=22)$ \\
\hline Expected survival time on ICU admission & $n(\%)$ \\
$<1$ week & $4(23)$ \\
$1-2$ weeks & $7(32)$ \\
$3-4$ weeks & $6(27)$ \\
$1-6$ months & 0 \\
$>6$ months & $12(4-53)$ \\
Actual survival time on ICU admission (day) & $10(46)$ \\
Consistency between the expected and actual survival times & $12(54)$ \\
If discordant, & $8(67)$ \\
Expected less & $4(33)$ \\
Expected more & $1(8)$ \\
Difference between the expected and actual survival times & $9(75)$ \\
Within 1 week & $2(17)$ \\
Between 1 week and 1 month & 0 \\
Between 1 month and 3 months & 0 \\
Between 3 months and 6 months & 0 \\
Between 6 months and 1 year & 0 \\
More than 1 year &
\end{tabular}

Values are presented as number $(\%)$ or median (interquartile range).

ICU: intensive care unit. 